\title{
EL CAMBIO POLÍTICO EN MÉXICO: UNA MIRADA DESDE ESPAÑA
}

\author{
Juan Francisco Escobedo Delgado*
}

El cambio político hacia la democracia en México, ha recibido un impulso que puede ser definitivo, en las elecciones parlamentarias y del Distrito Federal del pasado 6 de julio de 1997. Los resultados electorales fueron ostensiblemente desfavorables al PRI, perdió la mayoría en la Cámara de Diputados (con el 38.86\%, frente al 26.99\% del PAN, $25.59 \%$ del PRD, $3.86 \%$ del PVEM y $2.56 \%$ del PT), la elección de regente del Distrito Federal (el PRI consiguió el $25.08 \%$, el PRD con Cuauhtémoc Cárdenas a la cabeza el $47.11 \%$, el PAN $15.25 \%$ y el PVEM 6.74\%) y preservó la mayoría en el Senado con 76 de los 128 escaños que lo componen. Pese a los reveses, se mantiene como la primera fuerza electoral y política del país. Antes de formular un análisis plausible de lo ocurrido, conviene establecer las coordenadas del cambio político en perspectiva histórica, identificar algunos de los problemas y procesos fundamentales, y finalmente, analizar las tensiones políticas potenciales entre la institución presidencial, el PRI y la oposición, en el marco de la trama institucional vigente.

Como ayuda de memoria, téngase en cuenta que la caracterización del régimen político mexicano ha sido objeto de discrepancias entre los analistas, el consenso no es fácil dada la complejidad del fenómeno, como la insuficiencia de los esquemas ${ }^{1}$. La prematura admisión del régimen político en el club de las democracias ${ }^{2}$, impidió reconocerlo como lo que es, hasta los tiempos que corren: la variante mexicana del autoritarismo. La falta de consenso en el pasado, no ha sido obstáculo para el surgimiento de inesperadas coincidencias entre los analistas y críticos -pero no por ello, menos imprecisas- en torno a la naturaleza y resultados de la última jornada electoral, prohijados por un régimen que se democratiza.

\section{COORDENADAS HISTÓRICAS}

Si tomamos el año de 1977, como el inicio del largo proceso de liberalización ${ }^{3}$, con la reforma política de Jesús Reyes Heroles, estaríamos hablando de un ciclo de mutaciones en el régimen, que dura ya 20 años. Durante ese tiempo, el país ha vivido la declinación del modelo de desarrollo instaurado desde los años '40, basado en la matriz estado céntrica ${ }^{4}$, propiciado por la crisis económica de los años ' 80 , la política de ajuste y el programa económico sesgado hacia el mercado, que desplegó el gobierno.

Entre las elecciones presidenciales de 1976 y las elecciones parlamentarias de 1997, se realizaron 7 reformas electorales, que modificaron sustancialmente el aparato institucional y las reglas de la competencia, pero aún de manera insuficiente e incompleta, como para considerar que se haya agotado el ciclo reformista e instaurado plenamente las reglas básicas de la democracia. Excepto la última de las tres reformas de Salinas y la primera de Zedillo, las 5 reformas electorales que las precedieron, se realizaron bajo la iniciativa y amplio margen de definición de contenidos, por parte del gobierno. La oposición panista jugó un papel importante en la reforma de 1990, porque el PRI había perdido la mayoría calificada para modificar por sí sólo la Constitución, pero una vez que la recuperó en las

Doctorando en Ciencia Política en el Departamento de Ciencia Política y de la Administración I, Fac. de Ciencias Políticas y Sociología. Universidad Complutense de Madrid. Tesis en elaboración: "Persistencia y cambio político en México: las razones del pasado". E-mail: guadama@euc.max.sim.ucm.es. Agradezco a Luis Fernando Ostria, Maria Luisa González Bueno y Ana R. Casañas Sicilia sus enriquecedoras opiniones y sugerencias.

1. Giovanni Sartori sobre ésta cuestión opina: “a mi juicio, el caso mexicano atestigua, más que ninguna otra cosa, la pobreza y los errores de la tipología vigente de las comunidades políticas de partidos. Hay todo género de errores conceptuales, de interpretación y de predicción que son resultado de nuestra incapacidad para introducir en ningún marco adecuado al PRI mexicano, el famoso Partido Revolucionario Institucional", en Partidos y sistemas de Partidos, t. I, Madrid, Alianza Editorial, 1980, p. 281.

2. Samuel Huntington considera al régimen político mexicano inscrito en el grupo de países de la tercera ola que han transitado a la democracia. En la apreciación precipitada sobre México, ejerció poderosa influencia el impacto de las reformas económicas del gobierno de Salinas. El libro fue terminado antes del fatídico año de 1994 y no considera la insurrección guerrillera en Chiapas, ni la muerte del candidato presidencial del PRI; en La tercera ola. La democratización a finales del siglo XX. Barcelona, Paidós, 1994.

3. Kevin J. Middlebrok, "La liberalización política en un régimen autoritario: el caso de México", en Guillermo O’Donnell, Philippe Schmitter y Laurence Whitehead (eds.) Transiciones desde un gobierno autoritario, vol. 2, pp. 187-223.

4. Ludolfo Paramio, "El final de un ciclo y la crisis de unos actores: América Latina ante la década de los 90" y Marcelo Cavarozzi. "Más allá de las transiciones a la democracia en América Latina", en Revista de Estudios Políticos no. 74, 1991. pp.131-143 y 85-111, respectivamente. 
elecciones de 1991, el gobierno y el PRI volvieron a conducirse con los desplantes hegemónicos de otras épocas. En ninguna reforma electoral posterior a 1977, se puso en juego ninguna estrategia con horizonte de largo plazo, para conducir el cambio político hacia la democracia.

Se ha tratado de reformas legitimistas ${ }^{5}$, que buscaban en el marco de un "pluralismo restringido", prolongar la persistencia autoritaria del orden político. Pese a los problemas de legitimidad, a las dificultades para mantener el apoyo social y el consenso político, que ha vivido el régimen en las últimas dos décadas; hasta antes de 1994, ninguna fuerza política, ni conflicto social consiguieron que el régimen reaccionara rápido para asumir el imperativo del cambio político, como lo propició la eclosión guerrillera del Ejército Zapatista de Liberación Nacional en enero de ese año.

7 reformas electorales en 20 años son demasiadas y pueden dar idea a simple vista de un proceso acumulativo de cambios, dirigido con visión estratégica por el régimen y su timonel, el presidente del país. Cada administración gubernamental de las 5 que corresponden a éstos años, impulsó los cambios políticos mínimos para no perder la iniciativa política, restaurar la legitimidad cuestionada, dar cauce a la exigencias de contestación y participación política, cuidando de no poner en riesgo el triunfo del PRI, especialmente de su candidato presidencial. El reformismo legal ha combinado en proporción siempre distinta, estrategias de restauración y reconsolidación autoritaria, para enfrentar el riesgo que ofrecían ciertas tendencias electorales, como el aumento de la competitividad relativa, la segmentación electoral entre el campo y la ciudad. En ese sentido hizo concesiones a los reclamos democráticos de la oposición, pero mantuvo restricciones que descalificaban la credibilidad de las elecciones. La diferencia en credibilidad, organización y expresión del fraude entre las elecciones presidenciales de 1982, 1988 y 1994 es significativa. Pese a la inequidad y desconfianzas, la época del arrasamiento y feudalización de los procesos electorales, ha empezado a quedar atrás. Pero, pese a los avances para darle a los procesos electorales la credibilidad necesaria, la desconfianza entre los actores partidistas prevalece, porque no se han removido lo suficiente algunos de los factores que le dan al PRI una condición predominante en las contiendas electorales: financiamiento discrecional de su gasto corriente y sesgo monopólico y patrimonialista de los medios de comunicación electrónicos.

Tan honda llegó a ser la desconfianza en los procesos electorales, y tan fuertes los problemas de legitimidad del régimen, que éste se ha visto empujado a aceptar la pérdida gradual del control de las elecciones, mucho más de lo que estaba dispuesto a conceder hace 6 años, hasta el punto de verse impelido a tolerar que la responsabilidad de las elecciones recayese en una institución autónoma, diferenciada de la secretaría de Gobernación, y dirigida por personal independiente y elegido por los partidos. Si el coste político de la legitimidad y apoyo al régimen ha sido alto, el coste financiero no lo es menos; la inversión pública en infraestructura física, material y humana que se ha realizado para "producir confianza" es altísima. Pese al nivel de gasto, superior a lo que cualquier otro país de nivel de desarrollo similar a México, haya invertido en infraestructura electoral, no se puede afirmar que el trayecto hacia la instauración de la democracia, se haya recorrido cabalmente. Siguen pendientes por lo menos tres asignaturas sobre las que se ha bordado fino, pero sin llegar a fondo: financiamiento de los partidos que implique la transparencia del financiamiento y legalidad del patrimonio del PRI, acceso a los medios de comunicación con la correlativa revisión de la política gubernamental en materia de concesiones y la instauración de instituciones plenamente autónomas para resolver los contenciosos electorales.

Pese a las resistencias y bloqueos de los grupos duros del PRI al cambio político, el nivel de movilización ciudadana, organización partidista y competitividad electoral de la oposición, han aumentado de manera significativa durante los últimos 10 años. La comunidad política ${ }^{6}$ se ha estructurado y fortalecido, suscitando tensiones continuas en el régimen. De ahí que, después de cada reforma electoral y su correspondiente elección, haya seguido un desfasamiento que vino a reforzar las demanda recurrentes de la oposición para reformar la legislación apenas reformada. El régimen ha mantenido la iniciativa reformista, pero sucesivamente ha ido perdiendo autonomía y fuerza para imponer sus proyectos de restauración y ambiguo reformismo.

El ciclo de reformas a la legalidad electoral, está asociado a la tendencia de pérdida gradual de control del régimen, sobre segmentos cada vez más grandes e importantes de la comunidad política. En perspectiva de largo plazo, puede colegirse que el régimen ha seguido una política reactiva para responder a las demandas de participación política. Ha pasado del soliloquio de la reforma de 1977, a la reforma de 1994, negociada con todos los partidos, bajo la presión del conflicto chiapaneco. Hasta llegar a la reforma de agosto de 1996, que pese a que contaba con la disposición presidencial, se bloquearon todas las posibilidades de ser aprobada por consenso, y no sólo por la mayoría prísta como finalmente ocurrió. Se sabe que las negociaciones infructuosas acerca del financiamiento partidista se toparon con el muro infranqueable del régimen, que ha impedido desvelar el origen del gasto corriente y la legalidad del patrimonio físico del PRI. Es evidente que el régimen ha seguido una estrategia legitimista. $\mathrm{Ni}$ siquiera Zedillo pudo convencer a priori de su posición reformista. Son las actitudes asumidos ante hechos consumados los elementos que califican la posición del régimen y del gobierno, más allá de las intenciones y retórica. En momentos de desconfianza creciente, el gobierno zedillista no dudó en transferir la responsabilidad exclusiva de la credibilidad de las elecciones al Instituto Federal Electoral, que a cumplió su cometido en la fase actual del proceso transicional. Partidos, ciudadanos, medios de comunicación

5. Empleo el término "legitimista" de acuerdo al significado que reconoce el DRAE: "Partidario de un príncipe o de una dinastía, por creer que tiene llamamiento legítimo para reinar”. Madrid, 1977, vigésima primera edición, tomo II, p. 1240.

6. El concepto de comunidad política que tengo en cuenta para este análisis es el que desarrolla Leonardo Morlino en Como cambian los regimenes políticos, Centro de Estudios Constitucionales, Madrid, 1985. 
nacional e internacional han jugado su parte, para empujar el cambio político a partir de la derrota del PRI y pese a la indecisión y resistencias del régimen.

\section{VIEJA Y NUEVA COMUNIDAD POLÍTICA}

Con la crisis económica de los años 80 , se redujo el margen de acción que el régimen había ganado con la reforma de 1977. El reconocimiento al Partido Comunista en 1978, la Ley de Amnistía y la ampliación de la representación opositora en la Cámara de Diputados por la vía plurinominal, colmaron las demandas políticas centrales de la década de los sesenta, pero fueron insuficientes para albergar las tensiones derivadas de la inconformidad y movilización política de nuevos grupos sociales, asentados en las ciudades y políticamente más cercanos a la ideas y principios de la oposición de derecha, que a los grupos de izquierda. El PRI atrapado en la lógica corporativa y presionado por el chantaje de la CTM, por las exigencias de los gobernadores y, de los pequeños, pero poderosos caciques de importantes regiones del país, no pudo responder a los reclamos de los ciudadanos de clase media y media alta, que se resistían a ser encasillados en los esquemas de control, como a seguir tolerando la de ineficacia gubernamental y la impune corrupción de la élite gobernante.

El PAN tenía un buen sedimento organizativo y supo catalizar la movilización ciudadana de los años de la crisis, ofrecerle espacio de expresión y objetivos políticos de corto plazo, que le dieron un empuje definitivo para empezar a competir con fuerza en las elecciones locales de Chihuahua, Durango, Baja California y Juchitán en Oaxaca en 1983; Coahuila en 1984; San Luis Potosí, Nuevo León y Sonora en 1985 y la elección para gobernador de Chihuahua en $1986^{7}$.

El régimen cuidadoso de las perturbaciones al centralismo y al omnímodo poder presidencial, no contaba que las tensiones políticas viniesen de las regiones. No las esperaba y una vez en curso, no tuvo la visión estratégica de darles una respuesta adecuada. El punto de inflexión fue Chihuahua $^{8}$. La decisión de bloquear el ascenso de la oposición a la gubernatura de Chihuahua, no se derivó de concesiones a los grupos duros del régimen y del PRI; es probable, que se originase en el propio presidente Miguel de la Madrid y en su entorno, que veían en el reconocimiento de los triunfos panistas, un riesgo al modo autoritario con que estaban imponiendo el ajuste económico. En este período, la élite gobernante y el programa modernizador tuvieron su despegue y expresión autoritaria, pero luego serán superados en ortodoxia y autoritarismo por el gobierno de Carlos Salinas. Tras la fachada de hombre apaciblemente mediocre, que representaba el presidente, se agazapaba la estrategia más conservadora, para mantener los ajustes y el programa modernizador, echando mano de la eficacia del orden político tradicional. El gobierno no fue capaz de reconocer la oportunidad que le ofrecía el avance de la oposición, para introducir una dosis importante de legitimidad y margen de acción para su política. La reacción autoritaria y agraviante que se impuso en las elecciones de
1986 de Chihuahua, no atenuó el impulso ciudadano opositor, fortaleció las estructuras organizativas del PAN, le dio la justificación política adicional que le faltaba y preparó el terreno para la rebelión electoral de 1988. Que para quienes no se engañaban ante las tendencias electorales de las 4 elecciones federales previas, era previsible esperar problemas para el $\mathrm{PRI}^{9}$. En la que, además del afluente que representaba el panismo, recibirá la riada de movimientos sociales y ciudadanos, además de la participación contestataria de importantes segmentos de la élite mesocrática ${ }^{10}$ cuya respuesta se potenció con la del PRI en 1987, y que diseminados por todo el país se cohesionaron en torno a la candidatura presidencial de Cuauhtémoc Cárdenas.

Las elecciones locales de 1983 y 1984, y las elecciones federales de 1985 alertaron al régimen de las potenciales tensiones que podrían surgir si no flexibilizaba su resistencia a reconocer el avance de la oposición, y a dar paso a mínimas reformas a la legalidad electoral. Inmediatamente después de que se declaró electo al candidato príista a la gubernatura de Chihuahua en medio de la sospecha de fraude, el gobierno convocó a una serie de consulta públicas para discutir la reforma electoral. La reforma pretendía crear la trama legal que le permitiese al régimen conservar el poder, restaurar la legitimidad y la gobernabilidad. Introdujo una serie de reglas para garantizar que el PRI, aún en el escenario electoral más crítico, no perdiese la mayoría en la Cámara de Diputados. De ésta reforma data la famosa cláusula de gobernabilidad. Por el verismo con que dibujó sus excesos el régimen autoritario mexicano, conviene una apunte sobre tal dispositivo legal, como ayuda de memoria. La regla general establecía que al partido mayoritario se le otorgaría un porcentaje de representación igual al porcentaje de votos; considérese que la Cámara de Diputados se integraba con 500 diputados, 300 de mayoría relativa y 200 de representación proporcional. La regla tenía tres excepciones: 1.- ningún partido podría superar más del $70 \%$ de la representación, 2.- si ningún partido obtenía más del $50 \%$ de la votación, ni más de 251 diputados de mayoría, se le asignarían tanto los diputados necesarios hasta completar 251, y 3.- si un partido obtenía más diputados de mayoría relativa de los que le corresponden de acuerdo a la regla general, se le respetarán las victorias de mayoría relativa, de tal manera que se cumpliese el principio de que la mayoría relativa pudiese gobernar la cámara.

La reforma no previó todos los escenarios críticos, al introducir el principio de proporcionalidad en las instituciones que organizan las elecciones, que propició la exclusión

7. Juan Molinar Horcasitas. "Los procesos electorales: 1983-1987", en 17 ángulos de un sexenio. México, Plaza y Valdés, 1990.

8. Véase Juan Molinar Horcasitas, "Regreso a Chibuabua", Revista Nexos, núm 111, marzo de 1987, Enrique Krauze, "Chibuabua, ida y vuelta", en Por una democracia sin adjetivos, México, Joaquín Mortiz, pp.112-142.

9. Molinar Horcasitas, Los procesos electorales, ibídem. p. 159

10. Considero a la élite mesocrática como el segmento de las élites políticas que no llegan a formar parte del gobierno, ni participan como actores del proceso de sucesión presidencial y tampoco forman parte de los enclaves sindicales. Un análisis más amplio del tema lo desarrollo en mi tesis doctoral Persistencia y cambio de régimen político en México: las razones del pasado. 
en la estructura de decisiones de los "partidos paraestatales", de quienes el régimen no quería depender seguir dependiendo a la hora de las votaciones en el órgano federal electoral. Al excluir a los pequeños partidos de los mecanismos de negociación y protección electoral, los convirtió en potenciales agentes críticos. Este efecto no esperado de la reforma alcanzó dimensiones insospechadas, al confluir la candidatura de Cuauhtémoc Cárdenas, con la necesidad urgente que tenían los partidos-taxi de encontrar un resorte para reinsertarse en la vida política del país. Los partidos excluidos ofrecen el registro oficial como candidato y Cárdenas el liderazgo y capacidad de convocatoria social. La disolución inevitable del Frente Democrático Nacional después de las elecciones y la deserción de los partidos del proyecto de fundar un gran partido de "izquierda", confirmaron el sentido extraordinario y fugaz de la contestación crítica de los partidos que hasta entonces habían sido aliados del régimen, y que después del intermezzo electoral de ese año, volverán al redil del régimen.

El nacimiento del Partido de la Revolución Democrática constituye uno de los acontecimientos políticos fundamentales que habrán de estimular el proceso de declinación del régimen. No sólo porque terminó con la tendencia histórica a la que no habían escapado los movimientos rupturistas previos de 1940, 1946 y $1952^{11}$, que se disolvieron después de las elecciones en las que participaron, por disputas internas, problemas de liderazgo, hostilidad y represión del régimen. Con el neocardenismo, por primera vez en la historia, un movimiento rupturista cruzaba el umbral de la fatalidad, para dar paso a la formación de un partido que hiciera posible la continuidad de los impulsos sociales y políticos del movimiento contestatario. El PRD tuvo que soportar el vendaval del autoritarismo, sobrellevar las tensiones y conflictos internos de un movimiento que se resistía a dejar la calle para pasar a la organización partidista. En la travesía del desierto del PRD, no faltaron los efectos disuasorios y corrosivos derivados de las derrotas electorales de Cuauhtémoc Cárdenas y las múltiples y pequeñas derrotas en las elecciones locales, para empezar a madurar como partido. La llegada a la dirección nacional de Andrés Manuel López Obrador, líder del movimiento perredista de Tabasco, le ha empezado a dar aire y sentido estratégico a las relaciones con el gobierno y con el resto de los partidos, y ha propiciado una mejor actitud táctica de los perredistas para participar en los procesos electorales. Los resultados de éste viraje son múltiples y estimulantes para ésta formación política. Dos hechos confirman la eficacia de la nueva conducción política: la reforma electoral de agosto de 1996 y el triunfo de Cuauhtémoc Cárdenas en las primeras elecciones para elegir regente del Distrito Federal.

\section{RESTAURACIÓN LEGITIMISTA Y RECONSOLIDACIÓN AUTORITARIA}

Volvamos al contexto de las elecciones de 1988. Carlos Salinas se hace con la presidencia del país, en medio de un clima de tensiones crecientes y descrédito acerca de la verosimilitud de su triunfo. La promisoria coalición oposicionista forjada entre el candidato presidencial del PAN
Manuel J. Clouthier, Cuauhtémoc Cárdenas, candidato del Frente Democrático Nacional y Rosario Ibarra de Piedra candidata del pequeño Partido Revolucionario de los Trabajadores, para cuestionar la legalidad del proceso electoral e impugnar los resultados electorales, no llegará demasiado lejos. El régimen no está dispuesto a ceder, no acepta los reclamos de la oposición unificada, que pide una revisión minuciosa del proceso, y menos bajo el supuesto de una eventual derrota del PRI. Ante ese horizonte imperturbable, la oposición se ve en un dilema insalvable: o le otorga el beneficio de la duda al presidente electo de acuerdo con las cifras oficiales y le permite legitimarse en el gobierno, o asume una beligerancia total, exigiendo nuevas elecciones, proclamando su ilegitimidad y exigiendo la formación de un gobierno provisional que convoque a nuevas elecciones. La naturaleza de las candidaturas y de las estructuras políticas que les dieron soporte, definirán el sentido de las respuestas de la oposición a ese dilema.

El PAN decide capitalizar políticamente la fuerza electoral que se le reconoce oficialmente y en el documento que hace público el 16 de noviembre de 1988, denominado "Compromiso Nacional por la Legitimidad y la Democracia", ofrece sus razones y motivos ${ }^{12}$. El PAN advierte que el nuevo gobierno dispone de una estrecho margen para gobernar y que requerirá de apoyo político para hacerlo, que sólo el puede darle. Acepta el triunfo de Salinas, negocia una nueva reforma electoral sin definir los contenidos y abre paso a una inédita relación con el gobierno, que contra las críticas y malos augurios, no le causaron al PAN, daños políticos que le impidieran seguir avanzando electoralmente y empezar a ganar elecciones. El régimen encuentra un aliado y no desaprovecha la oportunidad. El PAN encuentra un punto de debilidad en el régimen y aprovecha la ocasión. Ambas partes se beneficiaron de las relaciones de conveniencia que establecieron, sin precedente en la historia del país. Es probable que a la larga, el mejor beneficiado haya sido el PAN; ya que en el lapso de un sexenio, paso de ser el partido de oposición que mejores resultados electorales locales obtenía, pero sin posibilidades de triunfo, a convertirse en el principal partido de oposición, gobernando importantes regiones del país y a consolidarse como el resorte básico de la gobernabilidad y una de las bujías del cambio político de régimen.

Las elecciones federales parlamentarias de 1991 demostraron la eficacia de la estrategia seguida por el régimen. El gobierno de Salinas no percibía la necesidad de introducir cambios políticos sustanciales en la reglas del juego e instituciones fundamentales del régimen. La comunidad política estaba fragmentada y polarizada, sin la menor posibilidad de exigir y presionar por una agenda de cambios posibles y negociables. La radicalización

11. Para un análisis detallado de los efectos de las rupturas de élite en el sistema electoral y en la conformación partidista, véase el libro de Juan Molinar Horcasitas, El tiempo de la legitimidad, México, Cal y Arena, 1991.

12. Luis Javier Garrido, "La transición a la democracia en México: los esfuerzos frustrados (1986-1992)", en Manuel Alcántara y Antonia Martínez (comps), México frente al umbral del siglo XXI, Madrid, Centro de Investigaciones Sociológicas, pp 162-167. 
del neocardenismo suscita reacciones defensivas, que muy pronto derivan en contraofensivas del régimen, bastante autoritarias. Mientras el PAN considera imprescindible la participación del gobierno y del PRI en la negociación y dirección de los cambios políticos que permiten las condiciones todavía muy favorables al régimen. $\mathrm{El} \mathrm{PRD}$ por su parte, se empeñó en desconocer al gobierno y exigir la disolución del PRI, al que considera "partido de estado" ${ }^{13}$. Los deseos perredistas no corresponden a la realidad del país. El error estratégico del PRD, lo descolocó del escenario de las negociaciones políticas durante el gobierno de Salinas; retrasando por seis años, la conformación de una comunidad política mejor organizada y capaz de imponer el desenlace definitivo a la transición democrática del régimen.

Pasada la tensión del proceso electoral, que mantuvo cohesionado el arco iris de grupos y movimientos que conformaron el movimiento neocardenista, la capacidad de movilización unificada empieza a menguarse. Los problemas de legitimidad que se acentuaron con la falta de credibilidad en el proceso y en los resultados, no derivan en una crisis generalizada de legitimidad. Las élites políticas mantiene su apoyo al régimen. Después de las elecciones no hay más rupturas. Los empresarios, que si bien miran con prudencia los acontecimientos, no dudan en reiterar su apoyo al régimen y al presidente electo. El ejército, al que constantemente había apelado Cárdenas durante la campaña, mantiene una discreta posición y cuando se hace necesario, ratifica su lealtad al régimen y al gobierno, reconociendo los resultados electorales oficiales. Los actores sociales tradicionales, salvo las tensiones internas que se viven en el sindicato petrolero y en el sindicato de maestros, se suman al alud de apoyos que recibe el candidato priísta electo. El apoyo no es unánime, la crítica al nuevo gobierno, además del PRD y grupos afines, viene de grupos con creciente influencia en la opinión pública, pero sin ser predominantes. En general, la comunidad política, los grupos intermedios, las élites, los empresarios no cuestionan la pertinencia del gobierno, y las iniciales reservas acerca del proceso electoral se difuminan rápidamente.

El gobierno de Salinas tiene prisa y mucha. Diseña objetivos y estrategias a la medida de cada conflicto y actor que se hubiese interpuesto en el camino. A todos los críticos de Salinas y del salinismo les llegará su momento de ajuste. Es necesario insistir en que, el despliegue político del gobierno de Salinas, pese a la grandilocuencia del discurso modernizador y al barniz democratizador con que encubrió sus decisiones y acciones políticas, se trató realmente de una estrategia de restauración legitimista y de recuperación del control político perdidos. Nunca tuvo la altura, la dimensión y los gestos convincentes como para considerar que se trataba de un típico proceso de transición democrática de régimen, dirigido por la élite gobernante.

No obstante las magnitud de las tensiones y conflictos derivados de la crisis de persistencia del régimen, todas las acciones políticas emprendidas estuvieron subordinadas a los objetivos de la política económica. Los problemas poselectorales no bastaron para modificar la percepción y el proyecto autoritario de transformaciones económicas que se proponía continuar y profundizar; acentuaron la obstinación por llevarlo a cabo, bajo el principio de que lo importante era reordenar la economía, y para conseguirlo no era necesario introducir cambios significativos en el viejo orden político.

Mientras discurría el gobierno de Salinas, no siempre quedó claro el sentido de sus acciones políticas. No pocos analistas mexicanos y extranjeros quedaron hechizados con la personalidad y las decisiones presidenciales, por cierto muy bien publicitadas en la prensa internacional; es célebre la postrera opinión de Tim Padgett corresponsal en México de la revista Newsweek: "Salinas nos becbizó e bizo olvidar que la política mexicana es un asunto bizantino y mafioso. Me bubiera ido mejor durante su presidencia si me bubiera acordado de una máxima que me dijeron cuando era un joven reportero en Chicago: "Si tu madre te dice que te quiere verifícalo" ${ }^{14}$.

No es un mérito menor, el haber utilizado el omnímodo poder presidencial para publicitar en los principales medios internacionales cada acción espectacular de su gobierno, para barnizar de modernizadores los ajustes de cuentas con los críticos. Es prodigiosa la trama que hizo posible superar los obstáculos que bloqueaban el programa modernizador y la política económica, pero de ello, a concluir que pretendiese cambiar de fondo las instituciones y reglas en que se sustentaba el orden político autoritario, hay una enorme distancia.

$\mathrm{Al}$ gobierno de Salinas le importaba recobrar margen de maniobra, afirmar su poder, dejar claro el mensaje del tipo de incentivos y castigos disponibles, según fuese la posición que se tomara ante el gobierno y sus políticas. No pretende modernizar la política, ni sus procesos ni a sus actores, busca con ambición desmedida tomar las riendas y el control del régimen, de sus resortes para exprimir toda la eficacia posible de la trama política, de modo que le permita cumplir con los objetivos de las políticas de ajuste y la instauración de un nuevo modelo de desarrollo económico. Se trataba de la vieja idea, de que cambiando la economía, el resto de la sociedad y de la política subordinadas a ella, habrían de cambiar también.

En el sexenio de Salinas se realizaron tres reformas electorales. Dos de ellas culminadas con el apoyo negociado del PAN, y la tercera, prácticamente urgente e impuesta por el curso de los acontecimientos incontrolables que se desencadenaron con la insurgencia del Ejército Zapatista de Liberación Nacional a partir del 1 de enero de 1994. Con las primeras dos reformas, se pretendió colmar de manera definitiva el problema de la legalidad, transparencia y credibilidad de los procesos y resultados electorales.

13. Pablo González Casanova, El Estado y los partidos políticos en México, México, Editorial Era,1981, y Luis Javier Garrido, El Partido de la revolución institucionalizada, México, Siglo XXI editores, 1982. Frente a la tesis de éstos autores, yo sostengo que se trata de un "partido de régimen”, en Las mutaciones del régimen político mexicano, ponencia presentada en el II Congreso Español de Ciencia Política, Santiago de Compostela, abril de 1996.

14. Tim Padgett, corresponsal jefe de la revista Newsweek en México, "Confesiones de un corresponsal gringo: también a mi me engañó Salinas", conferencia leída el 15 de febrero de 1996 en el Wabash College de Indiana, reproducida en la Revista Proceso no. 1033, 18 de agosto de 1996, pp. 8-9. 
Se dieron pasos significativos en la ruta hacia la instauración de un organismo autónomo, capaz de generar la confianza que el gobierno había perdido como organizador de elecciones. El régimen confiado en sus posibilidades de reafirmación electoral aceptó desmontar la trama de "proteccionismo electoral”, para edificar el Instituto Federal Electoral. A la distancia puede pensarse que se trató de una decisión estratégica del régimen, no fue así, la formación y consolidación de la nueva trama electoral, fue posible por las presiones y aumento creciente del poder de negociación de la oposición y el influjo de la opinión pública, que obligaron al régimen a ceder en cuestiones que hasta antes de las elecciones de 1988 no hubiese transigido.

Las piezas del edificio institucional que hoy es el IFE, se decidieron y luego se formaron, casi de manera geológica, en el curso de seis años y previas tres reformas electorales. Se trató de un proceso de aproximaciones sucesivas, que exhibió el nuevo territorio de las relaciones entre el régimen y la comunidad política. Si bien, ésta última no estaba en posición de fuerza unificada, como para obligar al régimen a seguir un curso determinado en el cambio político, tampoco el régimen podía imponer de manera unilateral todos los contenidos de sus proyectos reformistas como en el pasado, sin dejar de pagar costes políticos altos que podrían afectar la gobernabilidad del país.

\section{DECLINACIÓN AUTORITARIA}

El 30 de noviembre de 1993 fue el día más grandioso para el gobierno de Salinas, porque el Senado de Estados Unidos ratificó el Tratado de Libre Comercio. La élite gobernante vivió ese acontecimiento de manera exultante, como si fuese la culminación de una obra largamente esperada y con tanto sacrificio edificada. El marketing que insufló de espectacularidad las acciones del gobierno de Salinas, terminó alejándole de la sociedad a la que pretendía haber interpretado en sus aspiraciones. Las cuentas de la política económica desbordaban optimismo, pero los vasos comunicantes seguían bloqueados. Territorios enteros y segmentos sociales numerosos seguían ajenos a los beneficios del PRONASOL ${ }^{15}$, que no se conmovían con el desmesurado optimismo de la élite y de sus apologistas. La eclosión de un movimiento guerrillero en el centro del escenario en que se representaba la prosperidad y las virtudes del programa modernizador, constituyó un argumento irrebatible contra la imagen virtuosa, moderna, próspera y además democrática, que pretendió vender el gobierno. El muro del autoritarismo mexicano cedió con el impulso adicional de la insurrección chiapaneca, acto seguido empezaron a tomar su verdadera dimensión y a expresarse las contrahechuras y tensiones de un régimen que había logrado prolongar su persistencia por 5 años más, sin acusar de sus limitaciones y problemas de fondo.

No abundaré en los pormenores de las políticas gubernamentales de esos años, ni en sus consecuencias, que seguramente serán mucho mayores de lo que ahora se percibe. En cambio, quisiera subrayar la persistencia en su naturaleza autoritaria, de algunos de los procesos más representativos del régimen mexicano, cuya lógica se sigue preservando, pese a las mutaciones ocurridas, y que confirman la visión de corto plazo de la estrategia política que acompañó al despliegue modernizador del salinismo. Insisto en que se trató de una estrategia de restauración legitimista y de reconsolidación autoritaria.

\subsection{La sucesión presidencial de 1994}

El proceso de sucesión presidencial se reiteró en sus aspectos tradicionales. El presidente Salinas designó a Luis Donaldo Colosio, el PRI hizo la tarea de la intendencia y lo proclamó su candidato. Manuel Camacho, regente del Distrito Federal, miembro de la élite presidencial, no era el único de los "presidenciables", pero si fue el único agraviado que expresó públicamente su desafección con el elegido. Salinas encauzó rápidamente las tensiones, la cercanía de Camacho con el presidente le permitió ciertas licencias, como expresar su desacuerdo renunciando al nombramiento que el mismo le había otorgado, como secretario de Relaciones Exteriores. A Salinas muy poco le duraría el gusto de la jugada maestra que había hecho para allanarle el camino a su delfín. Escasamente dos meses dominó el horizonte de la sucesión, teniendo en un puño al sucesor y en otro, la administración del éxito rutilante que le proporcionaba la firma del TLC. El EZLN echó a perder los planes hegemónicos de Salinas y desveló el rostro áspero y la última mascarada del autoritarismo mexicano. La desafección camachista no derivó en una nueva ruptura de élite. El PRI entró en juego y con eficacia amarró los cabos sueltos y echó a andar la maquinaria electoral.

El asesinato de Colosio el 23 de marzo de 1994, cerró el ciclo histórico de relativa tranquilidad que había acompañado las campañas y elecciones presidenciales previas, desde que el 17 de julio de 1928, el católico León Toral asesina al presidente electo Alvaro Obregón. En ese arco histórico, al que corresponden 13 elecciones presidenciales, no faltaron las tensiones, la represión selectiva del régimen y las constricciones a la oposición, pero en ninguna caso, ningún candidato ni presidente electo o presidente en funciones terminó sus días asesinado.

Salinas tomó el control de los acontecimientos, llamó a los gobernadores y a los jefes del PRI a la residencia oficial de Los Pinos ${ }^{16}$, y allí, indujo la designación de Ernesto Zedillo, que prácticamente no tenía competidor. Todos los miembros del gobierno estaban impedidos constitucionalmente para ser candidatos, excepto Zedillo que había renunciado a la secretaría de Educación Pública para convertirse en Coordinador General de la campaña de Luis Donaldo Colosio. El presidente del PRI, Fernando Ortiz

15. Uno de los estudios más documentados sobre el PRONASOL es el trabajo de Denise Dresser, Neopopulist Solutions to Neoliberal Problems: México's National Solidarity Program, Current Issues Brief núm. 4, La Jolla, Center for U.S. -Mexican Studies, Universidad de California, San Diego, 1991.

16. El antecedente de una proceso similar, se encuentra en la reunión que después de la muerte de Obregón en 1928, convocó Plutarco Elías Calles en Palacio Nacional a los jefes militares del país, para persuadirles de la necesidad de que un civil fuese el presidente interino e inducir el nombre del elegido: Emilio Portes Gil. 
Arana, promovido por algunos personajes priístas de poca monta, dejó crecer la voces que especulaban con su nombre, pero en realidad no tenía ninguna posibilidad de ser el candidato sucesor de Colosio, ni contaba entre la élite gobernante y los grupos de presión del país, con el consenso necesario. Salinas le mandó atajar el rumor, renunciar públicamente a cualquier pretensión política y poner manos a la obra para organizar una nueva convención partidista que abrigase y proclamase la candidatura de Ernesto Zedillo. Así lo hizo, y eficazmente. El nuevo candidato que había surgió del azar, se debatía entre el asombro y la duda, en un clima creciente de sospecha acerca de la muerte de Colosio, la sombra de Camacho, la incertidumbre de las élites políticas y el enorme boquete que había abierto la guerrilla. Además ya caminaban con paso firme los candidatos opositores; de nuevo Cuauhtémoc Cárdenas, como candidato del PRD y el controvertido y dueño de una personalidad política que no causaba indiferencia, Diego Fernández de Cevallos, como candidato del PAN.

\subsection{La trama corporativa}

Por otra parte, la estructura y funcionamiento de la trama corporativa no había sufrido cambios significativos. Se había mostrado muy eficaz para controlar la demanda social que exigían las políticas de ajuste, y llegada la hora de la sucesión se proponía cobrar las facturas por los servicios que habitualmente prestaba al régimen y especialmente al presidente del país. Fidel Velázquez seguía siendo dueño del escenario de las negociaciones con el gobierno y con el PRI, y los términos del intercambio se cumplían satisfactoriamente para las partes. Sólo el antiguamente poderoso sindicato petrolero mostraba un liderazgo débil, desde que el 10 de enero de 1989, su líder real Joaquín Hernández Galicia "La Quina" había encontrado la cárcel en respuesta a su osadía de desafiar al régimen, que lo había encumbrado. El sindicato de maestros había ajustado cuentas con el auspicio de Salinas, con el viejo líder real Carlos Jongitud Barrios y se dirigía a protagonizar un proceso de renovación interesante. La trama corporativa hizo su parte, no desafinó con exigencias críticas ni demandas insuperables. Se contaba con ella, los días difíciles de rupturas, movilizaciones y tensiones que acaecieron en la campaña de 1988 habían quedado atrás y no parecía que pudieran repetirse.

\subsection{La trama electoral}

Los procesos electorales federales, pese a la nueva trama institucional responsable de organizarlos, las modificaciones introducidas en su desarrollo y la participación creciente de ciudadanos no declaradamente partidistas, en los órganos electorales, no pudieron despojarse a priori de la sospecha de fraude. Las reformas no fueron suficientemente amplias y hondas para agotar el ciclo hegemónico del PRI, que le ha permitido participar en condiciones ventajosamente desiguales frente a sus opositores. La certidumbre en los resultados electorales fue siempre un factor controlado por el régimen.
Asociado al reformismo legal electoral, persistió el "proteccionismo electoral" y constricciones al pluralismo. El gobierno de Salinas no incurrió en el error de la reforma electoral de 1986, que había dejado huérfanos a los partidos paraestatales, obligándolos a ofrecerle el registro como candidato presidencial a Cárdenas. Para atenuar el crecimiento de la oposición real, se echó mano de la oposición paraestatal, reinsertándola en los órganos electorales, ofreciéndole garantías de acceso a la Cámara de Diputados, y manteniéndoles el flujo de financiamiento necesario para evitar su extinción de muerte natural.

El Partido Popular Socialista (PPS), el Partido Auténtico de la Revolución Mexicana (PARM) y el Partido del Frente Cardenista de Reconstrucción Nacional (PFCRN) no obstante los discrecionales apoyos y votos que el régimen les adjudicaba, no pudieron en el curso de los seis años del salinismo, menguar la base social ni el potencial crecimiento organizativo y electoral del PRD, mucho menos del PAN. La rebelión electoral de 1988, con sus efectos en el sistema de partidos y en el alineamiento electoral de los ciudadanos no había sido una eclosión azarosa, en su potencial disruptivo confluyeron tendencias políticas y electorales de largo aliento, que hicieron mezcla explosiva con el agotamiento de un modelo de desarrollo y un orden político que encontraba severas dificultades para seguir persistiendo en condiciones autoritarias. El antiguo escenario de control del pluralismo y manipulación sin consecuencias de los procesos y resultados electorales, llegó a su fin en 1988. A partir de entonces la oposición panista y neocardenista, con la inflexión electoral y organizativa que les representó el proceso de ese año, empezaron a inyectarle a las contiendas políticas una nueva tensión competitiva y poblaron de actores, movilización, negociación y conflictos de intereses la arena electoral de la política, antes colonizada por el PRI y la constelación de intereses que representa.

\section{FINAL DEL SALINISMO Y GOBIERNO DE ZEDILLO: ELECCIONES CREÍBLES Y NUEVA OPORTUNIDAD CON TIEMPO RESTRINGIDO}

El sedimento social y político del actual pluralismo, tanto en su expresión partidista, como en la composición de los órganos de representación nacional, venía fermentándose desde la conmoción de 1968 , pero alcanza su punto de ebullición en 1988. El sistema partidista basado en un partido predominante y dos partidos opositores con capacidad de triunfo y de gobierno, es realmente novísimo. La débil tendencia bipartidista de la que se habló hasta la saciedad a la luz de las elecciones de Chihuahua de 1985 y del triunfo panista en las elecciones para gobernador en Baja California, se desvaneció en las elecciones parlamentarias y del Distrito Federal del 6 de julio de 1997.

En el plazo de 9 años, el régimen y su partido desplegaron un alud de estrategias y acciones políticas para prolongar el predominio príista y la hegemonía del poder presidencial. Superaron los peores augurios, mostrando signos de eficacia prodigiosa para rehacerse en condiciones 
adversas, pero, pese a los éxitos relativos de la política legitimista, no pudieron suturar con la misma habilidad las rupturas y desajustes que la comunidad política provocaba en el régimen.

No entraré a explorar las causas que estimularon el proceso de movilización ciudadana y mayor capacidad de contestación y participación de la comunidad política, sólo insisto en la pertinencia de analizar algunos de los procesos fundamentales del régimen en el contexto de las elecciones presidenciales de 1994.

El PRI y su candidato Ernesto Zedillo se hicieron con el triunfo legalmente. Durante la campaña, especialmente a partir del primer debate del 14 de mayo de 1994, protagonizado por los tres principales candidatos a la presidencia, que fue ganado de manera contundente por Diego Fernández de Ceballos, la incertidumbre se instaló en las percepciones del régimen y las encuestas posteriores al debate que por primera vez en la historia no favorecían al candidato prísta. Por otra parte, los efectos disruptivos del conflicto chiapaneco seguían expandiéndose. El riesgo de la violencia empezó a percibirse como una cercana posibilidad. El PAN se encontró en dificultades para capitalizar el impacto político que había significado la contundente participación de su candidato en el debate, y con el curso de los días se le fue escurriendo la ventaja, esfumándosele la efímera posibilidad de derrotar al candidato oficial. Llegado el día de las elecciones recibió un apoyo electoral significativo que le colocó como la segunda fuerza política del país.

El PRD y su candidato Cuauhtémoc Cárdenas vivieron una estrepitosa caída en sus expectativas electorales. Después del vapuleo que recibió Cárdenas en el debate, no pudo presentar una imagen distinta a la que había mostrado hasta entonces, como un político obstinado e intransigente. La baja proporción de votos recibidos confirmó lo erróneo de su estrategia. Aún así, resistió el vendaval, evitó la dispersión a que le llevaba la inminencia del hundimiento y se aferró a una base social y élite partidista socializada en la movilización continua, que encontraban justificación a sus posiciones en la idea discutible, de que representaban la auténtica y legítima oposición a las políticas salinistas.

Si Cárdenas pretendió reeditar la campaña política de 1988 se equivocó ${ }^{17}$. Además, en un momento definitorio de la campaña de 1994 tuvo la mala inspiración de entrevistarse con el subcomandante Marcos en la selva chiapaneca. Los efectos comunicativos no pudieron ser más adversos. Marcos ganó mucho más que Cárdenas, tendió puentes hacia el espectro partidista, se dio el lujo de reprender a los perredistas y de paso afianzó la adhesión a sus consignas de un segmentó importante de la élite perredista. Cárdenas pagó caro su falta de visión estratégica. Desoyó la opinión que le aconsejaba distanciarse de cualquier signo, circunstancia o actor que representase la violencia. Se olvidó que el mejor antídoto contra la violencia es la posibilidad de que los ciudadanos ejerzan su derecho a elegir.

El presidente Salinas salió bien librado de su última asignatura electoral. Recupera margen de acción, restaña su imagen y vela sus armas para saltar a la escena internacional una vez que hubiese dejado la presidencia. Llega la toma de posesión de Ernesto Zedillo el 1 de diciembre, pero el idilio y el "milagro salinista" se viene abajo con la crisis que explosiona el 19 de diciembre. El telón cae estrepitosamente, nadie quiere asumir la responsabilidad de los errores cometidos. Salinas pasa a la ofensiva y se niega a reconocer que no sólo ha mentido al país, acerca de la situación económica en los meses posteriores a la muerte de Colosio, sino que ha cometido el error de no devaluar a tiempo la moneda, de ocultar la fuga de capitales y la reducción de las reservas del Banco de México. Salinas elude su responsabilidad, porque abriga la ambición de convertirse en el presidente de la Organización Mundial de Comercio, pero Zedillo no puede eludir su responsabilidad presente y tiene que actuar y decidir. No hay opción posible, el presidente en funciones tiene que dar la cara, aún a costa del descrédito del expresidente y del desvanecimiento de sus ambiciones. Una vez más, se reitera una vieja tendencia histórica, en la disputa entre un expresidente poderoso y el presidente en funciones, en medio de una crisis de legitimidad del régimen y de sus componentes fundamentales, donde siempre ha vencido el presidente en funciones. El mito de Salinas, de la irreprochabilidad de su programa, de la honestidad de su gobierno y el poder político acumulado e indisoluble, se derrumbaron súbitamente.

Las tensiones entre las élites políticas vuelven a colocarse en el centro del escenario de crisis de persistencia del régimen autoritario. El presidente deambula como rehén de los grupos en pugna, No tiene otra salida en los meses inmediatos que apoyarse en la nueva correlación de fuerzas partidistas configurada por las elecciones de agosto de 1994. Rompe con el monopolio priísta y la línea sucesoria de la élite gobernante e incorpora a su gobierno al panista Antonio Lozano como Procurador General de la República. Las tensiones políticas van en aumento, porque las élites han caído presas de la inseguridad que se percibe en el país. Asesinatos impunes, incapacidad estatal para generar confianza y esclarecer las muertes políticas. La sombra del narcotráfico y su constelación de intereses y efectos se cierne sobre el gobierno. Si esto no fuera suficiente, a los ya imponentes problemas que generaron los errores en el manejo de la política económica, se añaden los escándalos de corrupción y complicidad en que se ve involucrada la familia de Salinas. En un sólo aluvión de conflictos en ebullición, se ha conmovido hasta la ignominia, el escarnio y el linchamiento público la persona y la obra del penúltimo presidente imperial ${ }^{18}$.

Tres factores que no habían aparecido en los años previos, saltan a la escena para acelerar el quiebre de la unidad de las élites políticas: el expresidente Salinas elude la responsabilidad de los errores de gestión de la política económica y osa desafiar al régimen para defender su prestigio difícilmente justificable; eclosiona la cloaca de la corrupción y esta vez, los responsables y las complicidades rondan

17. Adolfo Aguilar Zínser, ;Vamos a ganar! La pugna de Cuaubtémoc Cárdenas por el poder. México, Editorial Océano, 1995.

18. Enrique Krauze, La presidencia imperial. Ascenso y caida del sistema politico (1940-1996), México, Tusquets Editores, 1997. Véase especialmente el capítulo "Carlos Salinas de Gortari, El hombre que quería ser rey". 
la persona y la familia del expresidente; la opinión pública y particularmente los príístas agraviados desde la muerte de Colosio y la desafección que les provocaron los múltiples y contradictorias decisiones y acciones públicas para esclarecer los asesinatos de Colosio y Ruiz Massieu, les llevan a exigir un enjuiciamiento político y judicial y la correlativa expulsión del PRI del expresidente trashumante.

El centro de las demandas de desagravio es el presidente Zedillo, y ésta vez, como en el pasado no hay forma de atenuar o controlar las exigencias de los priístas, con incentivos de otra naturaleza. El PAN y el PRD actúan con prudencia y astucia, y muy pronto consiguen que tales crímenes se perciban como problemas entre prístas y no necesariamente como problemas del país. No les falta razón, la crisis de persistencia del régimen, les concierne, pero de ahí no se sigue, que el conjunto de los partidos tengan los mismos problemas del PRI y mucho menos que deban asumirlos como propios.

No se trata de una crisis de los partidos, ni del sistema de partidos, ni tampoco se reduce a un problema de representación política, se trata de la agudización de las tensiones propias de una crisis de régimen político, que exhiben sus limitaciones para procesar los conflictos y los asuntos que plantea la comunidad política y la propia naturaleza de las estructuras políticas en condiciones autoritarias. Las consecuencias se advertirán en las elecciones del 6 de julio de 1997.

El gobierno de Zedillo intenta establecer una línea de diferencia con el PRI. Propone establece una relación de "sana distancia", que no es entendida ni percibida como definitiva. Los grupos más duros y las organizaciones sociales tradicionales del PRI, torpedean la estrategia presidencial. Muy pronto se exhibe lo inoperante de la medida. El apoyo y consenso que el PAN comprometió al gobierno con la presencia de uno de sus cuadros políticos importantes en el gobierno, termina truncado, por el fracaso de la gestión del procurador para esclarecer los asuntos judiciales más importantes. Zedillo se deshace del compromiso panista y entonces se da cuenta de que está aherrojado por los "duros". Ya no tiene el apoyo y consenso del PAN, y el PRD no está dispuesto a vender barata su relación con el presidente. Los priístas viven extrañados por la que consideran injustificada actitud de Zedillo, de cambiar el trato con ellos, como si bastara un discurso para desmontar la compleja relación simbiótica, tejida desde 1930 cuando los ámbitos del gobierno y del PRI empezaron a mezclarse hasta confundirse. El viraje no se hace esperar, Zedillo rehace la relación con el PRI, evita la ambigua y nada convincente "sana distancia", para volver a la vieja relación subordinada del PRI hacia el presidente. Al mismo tiempo, se ve obligado a abrir un proceso de diálogo con los partidos de oposición representados en la Cámara de Diputados ( PAN, PRD y Partido del Trabajo ) para impulsar una nueva reforma electoral.

No hay visión estratégica, hay reacciones tácticas, medidas de coyuntura para evitar el angostamiento de los márgenes de acción. Sólo se advierten nuevos matices en la percepción de los problemas que se suceden en el país. El gobierno mantiene la política de ajuste, pero esta vez, para asegurarse de su cumplimiento y especialmente del uso transparente de la ayuda financiera, la intervención de Estados Unidos es inevitable. La crisis adquiere dimensiones insospechadamente desestabilizadoras, pero ahora, México cuenta con un socio poderoso, que tiene que pagar el precio de la alianza. Esta vez, no son sólo los efectos internos, sino las consecuencias internacionales de la crisis económica mexicana, lo que lleva a reaccionar tan rápida y favorablemente al poderosos vecino. Es el temor a la generalización y duración del "efecto tequila" lo que viene en ayuda del gobierno, cuya eficacia ha caído peligrosamente, impactando corrosivamente la legitimidad del régimen.

Zedillo tiene la legitimidad y la autoridad que no tenía Salinas en los primeros días de su gobierno, pero carece del margen necesario para actuar, y además no está en condiciones de mejorar las condiciones de bienestar de la mayoría de los mexicanos, tan sólo puede comprometerse a restaurar lo perdido y no en un plazo corto. Su gobierno soporta el deterioro de las condiciones de vida de los ya lastimados pobres de México, que no disponen de mecanismos efectivos de expresión y canalización política de su inconformidad, ya que en su mayoría se hayan vinculados a alguna estructura o mediación política priísta. Pero las tensiones críticas vienen de los grupos sociales con mejores niveles de ingreso, que ven frustradas su expectativas por las constricciones bancarias que derivan de la crisis y que les arrebatan ingresos, capital invertido y patrimonio familiar. Estos grupos crean sus propios mecanismos de expresión y movilización, que llegar a alcanzar dimensiones muy beligerantes. Entre los grupos más conocidos destaca "El Barzón”. Los grupos sociales afectados que no se vuelven "barzonistas", ni crean nuevas organizaciones, introducen demandas críticas en sus organizaciones tradicionales, transitan hacia los ámbitos partidistas opositores, o bien, aguardan la mejor oportunidad de pasarle factura al gobierno, al que ven como responsable de la frustración de su progreso. Si consideramos el lapso que va de 1980 a 1997, tenemos que la sociedad mexicana ha vivido en 17 años la pérdida de la obra material, el desarrollo humano y los sueños de prácticamente un generación entera.

En la formulación de una explicación plausible de lo que ocurrió en las elecciones pasadas, debe considerarse la dimensión local de la arena electoral. Los resortes de la oposición panista se encuentran en su capacidad de disputarle al PRI territorios de poder en las regiones del país, desde mucho tiempo antes de que el régimen se decidiese a reconocer sus victorias. El ciclo de éxitos electorales, conquista de posiciones políticas determinantes y expansión organizativa del panismo tiene su punto de inflexión en el salinismo, con altibajos en la administración de Zedillo. La vertiente regional o local de la contienda electoral, permite advertir el rostro del autoritarismo declinante en sus diversas facetas, por un lado, el desarrollo e implantación desigual de la oposición, que aumenta su nivel de competitividad electoral, y por otro, la existencia de enclaves autoritarios priístas, donde las elecciones han arrojado resultados en los que la distancia entre las primera y la segunda fuerza electoral, sigue siendo superior al 
$20 \%$ de los votos emitidos. es decir, territorios fértiles para la persistencia de la hegemonía priísta.

La dimensión presidencial de la arena lectoral sigue siendo favorable al PRI. En tal contienda, donde impera la lógica del todo o nada, la oposición pese a su mayor potencial electoral, aún no prueba su capacidad de darle la vuelta a los resultados y derrotar al PRI. El PRD quedó atrapado desde su fundación en la lógica de la lucha por el poder presidencial y es en ese juego desigual donde el PRI aún no ve su suerte, ni conoce su verdadero piso electoral. No consiguió ningún triunfo electoral en las elecciones de gobernador que se disputaron durante 9 años. Pese a su ineficacia electoral, conservó su principal capital político, la figura política, obstinadamente crítica de Cuauhtémoc Cárdenas, que supo moderarse a tiempo para ganar de manera contundente la elección de Jefe de gobierno del Distrito Federal.

De un golpe, los dos partidos opositores más importantes han conquistado el suficiente poder público, como para cerrar el ciclo de la hegemonía prísta en el parlamento y obligar al régimen a concluir la agenda mínima de cambios políticos que hagan posible que las elecciones, desde antes de celebrarse gocen del prestigio y confianza necesarios, como para afirmar que ha terminado por instaurarse un régimen plenamente democrático. El nuevo horizonte en la correlación de fuerzas, que le dan a la comunidad política la capacidad necesaria para rehacer al régimen, es prometedor para el cambio político, pero no debe pasarse por alto, que los procesos políticos más importante para el PRI y el régimen autoritario declinante lo constituyen: por un lado la designación del candidato presidencial del PRI y por otro, las elecciones presidenciales. Hasta ahora, ambos procesos no han cambiado sustancialmente y el PRI no ha sido vencido en una elección presidencial. El PRI aún debe probarse en su capacidad para sobrevivir a una eventual derrota, sin intentar una regresión autoritaria. En el plazo que va de 1997 al año 2000, fecha de las próximas elecciones presidenciales, el PAN, el PRD, y los pequeños Partido del Trabajo y Partido Verde Ecologista de México, que consiguieron escaños en el parlamento, tienen el enorme desafío de dar el jalón definitivo a la transición democrática. Que como he intentado analizarlo en éstas páginas, tiene ya un largo recorrido sobre sus espaldas. Sin embargo, hay que conservar las reservas necesarias para no caer en el desencanto, porque como escribiera Alfonso Reyes: "El pasado inmediato es, de alguna forma el enemigo".

\section{RESUMEN}

Este ensayo considera que la transición a la democracia en México está inconclusa. Los resultados electorales del 6 de julio de 1997, terminaron con siete décadas de monopolio del PRI en el parlamento federal y con la prohibición de los derechos políticos de los ciudadanos de la Ciudad de México. Los cambios en la relación de fuerzas entre partidos, se inscriben en el largo ciclo de mutaciones y reformas, que empezó con el despegue liberalizador de 1977. Durante el gobierno de Carlos Salinas (1988-1994), se desplegó una estrategia de restauración legitimista, que hizo posible la reconsolidación autoritaria del régimen. El gobierno de Ennesto Zedillo enfrenta las tensiones de un régimen autoritario en crisis, con una política reactiva y ambigua. El presidente no se decide a liderar el cambio político hacia la democracia, tanto tiempo postergada.

Palabras clave: Cambio Político - México - Democracia - Reforma Política.

\section{ABSTRACT}

This essay takes into account that the transition to democracy in México is unfinished.The electoral results of the 6 july in 1997 terminate with seven decades of PRI's monopoly in the federal parliament and with the forbid of political rights of citizens the City of Mexico. The changes in the balance of power among parties it's record in the long cycle of mutations and reforms that began with the take off reformist in 1977. During the Carlos Salinas' government (1988-1994) the authoritarian regime it's reconsolidated. Ernesto Zedillo's government to put face the stress of the authoritarian regime in crisis, with a reagent policy and ambiguous, The president don't decide to practice as leader of the political change to democracy for a long time delay.

Key wors: Political Change - México - Democracy - Political Reform. 